\title{
Treatment of Hepatitis C with Pegylated Interferon Alpha-2a and Ribavirin: Experience from Benin
}

\author{
Aboudou Raïmi Kpossou1* ${ }^{*}$ Jean Séhonou${ }^{1}$, Gbénagnon Micaël Géraud Adjigbé1, \\ Rodolph Koffi Vignon', Khadidjatou Saké Alassan², Nicolas Kodjoh ${ }^{3}$
}

\footnotetext{
${ }^{1}$ Department of Gastroenterology and Hepatology, National University Hospital Center-Hubert Koutoukou Maga (CNHU-HKM), Cotonou, Benin

${ }^{2}$ Internal Medicine Unit, University and Departmental Hospital of Borgou-Alibori, Parakou, Benin

${ }^{3}$ Clinic Les Archanges, Sèmè Kpodji, Benin

Email: ^kpossou.raimi@yahoo.fr, jsehonou@yahoo.fr, poilond@yahoo.fr, rkvignon@yahoo.fr, khadisak@yahoo.fr, nicolaskodjoh@gmail.com
}

\begin{abstract}
How to cite this paper: Kpossou, A.R., Séhonou, J., Adjigbé, G.M.G., Vignon, R.K., Alassan, K.S. and Kodjoh, N. (2018) Treatment of Hepatitis $\mathrm{C}$ with Pegylated Interferon Alpha-2a and Ribavirin: Experience from Benin. Open Journal of Gastroenterology, 8, 275-283.

https://doi.org/10.4236/ojgas.2018.88030
\end{abstract}

Received: June 25, 2018

Accepted: August 5, 2018

Published: August 8, 2018

Copyright $\odot 2018$ by authors and Scientific Research Publishing Inc. This work is licensed under the Creative Commons Attribution International License (CC BY 4.0).

http://creativecommons.org/licenses/by/4.0/

\begin{abstract}
Background: Viral hepatitis C (HCV) is common in Benin. Untreated, it can be complicated by cirrhosis and hepatocarcinoma, which are sources of death. The objectives of this work were twofold: 1) to evaluate the effectiveness and safety of treatment with classic dual interferon pegylated alpha-2a (IFN) and ribavirin therapy in Benin, and 2) to present problems related to financial accessibility to this treatment. Methods: This was a cross-sectional, descriptive and analytical study, with a retrospective collection of data from November 1, 2010 to December 31, 2015 and prospective collection from January 1, 2016 to July 31, 2016 (7 months). We included all patients treated with IFN + ribavirin for hepatitis $\mathrm{C}$ at $\mathrm{CNHU} / \mathrm{HKM}$. Sustained virological response (SVR) was defined as undetectable viral load C 6 months after stopping treatment. Safety was appreciated by the search for clinical and hematological adverse effects. Results: One hundred and six patients were followed for HCV, of whom 58 (54.7\%) undergoing treatment (26 under standard dual therapy and 32 under direct-acting antivirals). Of the 26 patients underconventional dual therapy, $12(46.1 \%)$ were genotype 1,13 (50\%) genotype 2 and one (3.9\%) genotype 4. In conventional dual therapy, SVR was achieved in $15(57.7 \%)$ patients, including the genotype 4 patient, 4 out of $12(33.3 \%)$ genotype 1 patients, and 10 out of $13(76.9 \%)$ for genotype 2 patients. The most common side effects with this treatment were severe asthenia ( 23 cases), flu-like symptoms (22 cases), weight loss (21 cases) and neutropenia (22 cases), anemia and thrombocytopenia (20 of 26 cases). The overall cost of treatment per patient was $11,800,624$ FCFA for genotypes 1 and 4; and
\end{abstract}


7,835,048 FCFA for genotype 2. Conclusion: The treatment of HCV with IFN + ribavirin in Benin is effective for genotype 2. But its adverse effects are manifold and its cost is high. The switch to direct-acting antivirals (more effective, better tolerated and less expensive) was therefore necessary.

\section{Keywords}

Hepatitis C, Pegylated Interferon Alpha-2a, Ribavirin, Effectiveness, Safety, Cost

\section{Introduction}

Viral hepatitis is defined as any diffuse inflammatory process of the liver due to viruses with dominant hepatic tropism [1]. There are five types of viruses: A, B, C, D and E. But only some of them can cause chronic hepatitis. These are mainly hepatitis B and $C$ viruses that will therefore be the subject of therapeutic drug management. Hepatitis E virus can also give chronic forms but only in immunocompromised individuals.

The World Health Organization (WHO) estimated in 2015 to 71 million, the number of chronic carriers of the hepatitis $\mathrm{C}$ virus (HCV) worldwide [2]. Nearly $63 \%$ of those infected before the age of 40 progress to chronic infection with a $5 \%$ incidence of cirrhosis in 20 years and an annual mortality from chronic liver failure of $3.7 \%$ after the onset of cirrhosis [3] [4]. HCV infection is a major public health problem in developing countries. WHO estimates that in some countries, such as Egypt and Cameroon, its prevalence would be 10\% to 15\%. In Benin, it is estimated at $4.12 \%$ in blood donors [5]. The chronic forms of hepatitis B and C are most often the cause of death by their complications which are cirrhosis and hepatocellular carcinoma. But, effective treatments are available to avoid the occurrence of these complications and to obtain healing.

Although treatment for viral hepatitis $\mathrm{C}$ (VHC) has been around for many years and is widely used in developed countries, the high cost of pharmaceuticals (pegylated interferon and ribavirin) and pre-, per-, and post-treatment assessment has long been a brake on its implementation in developing countries, including Benin. Since 2010, a subsidy granted by the State allowed to begin in Benin a therapeutic management of the VHC. Two treatment regimens are available: traditional dual therapy (interferon + ribavirin) used since 2010 and direct-acting antivirals (DAAs) since the end of 2015.

No previous study has addressed the treatment of hepatitis $C$ in Benin. The objectives of this study were to evaluate the effectiveness of the treatment by conventional dual therapy of patients with VHC in Benin as well as the tolerance and the cost of this treatment.

\section{Methods}

This study took place in the University Clinic of Hepato-gastroenterology of 
CNHU-HKM in Cotonou. This was a cross-sectional study, retrospective from November 1, 2010 to December 31, 2015 (62 months) and prospective from January 1, 2016 to July 31, 2016 (7 months). Systematic and exhaustive recruitment was carried out in all the patients followed in the department for chronic hepatitis $\mathrm{C}$ during the period and placed on conventional dual therapy. The conventional dual therapy included pegylated interferon alpha-2a 180 $\mu \mathrm{g} /$ week subcutaneously plus ribavirin 800 to $1200 \mathrm{mg} / \mathrm{day}$ per os. Patient consent was obtained prior to inclusion in the study. Among them, were selected those in whom a therapeutic response was evaluable (treatment completed with a viral load carried out 6 months after the end of treatment). Sustained viral response (SVR) was defined as undetectable viral load C 6 months after the end of treatment. The biochemical response was based on normalization of aminotransferases. Safety was assessed by looking for clinical and biological side effects (patients were reviewed every 2 weeks the first month and then once a month). The data was collected on a survey card. This collection was done in part through a direct interview with socio-demographic variables (age, sex, occupation, religion, marital status, level of education, monthly income) and clinical variables (history and comorbidities). The collection was done also by consultation of the medical files allowing to note variables: clinical (the general state based on the index of performance status according to the World Organization of the Health (WHO), the mode of discovery, the main clinical signs) and paraclinical (initial viral HCV load, initial aminotransferases levels, genotype for HCV, liver biopsy puncture results or non-invasive liver fibrosis tests, abdominal ultrasound findings); therapeutics (treatment-related side effects classified by WHO toxicity grade and evolution data i.e. SVR, biochemical response, relapse or death). For statistical analysis, the data was recorded with the EPI Data 3.1 software and analyzed in the EPI Info 3.5.1 software. For frequency comparison, the $\mathrm{Chi}^{2}\left(\mathrm{x}^{2}\right)$ test was used. A $\mathrm{p}<0.05$ was considered as evidence of a statistically significant difference.

\section{Results}

\subsection{Characteristic of the Studied Population}

A total of 1,764 patients had been received for consultation in the department during the study period. Among them, 106 patients (6\%) had hepatitis C, including 5 cases of co-infection with hepatitis B virus and 1 case of co-infection with HIV.

Of the 106 patients followed for hepatitis C, 52.8\% (56 patients) were genotype 2, $46.2 \%$ (49 patients) genotype 1 and $0.9 \%$ (1 patient) genotype 4. Among them, 58 patients (54.7\%) were treated for VHC (including 27 genotype 1 patients, $46.6 \%$, 30 genotype 2 or $51.7 \%$ and one genotype 4 or $1.7 \%$ ). Of the 58 patients treated, 26 were treated with conventional dual therapy and 32 with DAAs. The results for patients on AAD are the subject of another article.

Regarding patients under conventional dual therapy, their age ranged between 
32 and 76 years with an average age of $57.53 \pm 10.78$ years. The most represented age group was 55 years and over. There were 16 men and 10 women with a sex ratio of 1.6. The majority of the treated patients were civil servants and especially senior managers (11 patients i.e. $42.3 \%$ ) and middle-grade managers (7 patients i.e. $26.9 \%$ ). The majority of patients (16 patients or $61.5 \%$ ) had a monthly income above 200,000 FCFA; with extremes ranging from 95,000 to 1,700,000 FCFA.

The discovery of $\mathrm{HCV}$ was most often made during routine screening (10 patients or $40 \%$ ). About $57.7 \%$ (15 out of 26) had clinical symptoms. This symptomatology was marked by digestive manifestations (in 7 cases) dominated by abdominal pain especially of the right hypochondrium (3 cases) and constipation ( 2 cases). Most extradigestive manifestations were marked by physical asthenia (4 cases). HCV was often not accompanied by repercussions on the general condition (performans status according to the WHO to 0 in 22 cases i.e. $84.6 \%$ ). No case treated with dual therapy had co-infection with either HBV or HIV. The main comorbidities were hypertension and obesity (11 cases, or $42.3 \%$ for each). It should be noted that 9 out of 26 patients (34.6\%) had cirrhosis (defined by F4 Fibrotest fibrosis or hepatic biopsy puncture, or an APRI score $\geq 2$ ); of which 6 of genotype 1 and 3 of genotype 2 .

The 26 patients treated with dual therapy were mostly genotype 2 (13 patients, $50 \%$ ). Genotype 1 represented 46.1\% (12 patients) and there was only one patient of genotype 4. Aminotransferases were initially elevated in $80 \%$ (21 cases). The viral load was less than $800,000 \mathrm{IU} / \mathrm{mL}$ in 15 patients (64\%), with extreme values of $31,903 \mathrm{IU} / \mathrm{mL}$ and $9,267,251 \mathrm{IU} / \mathrm{mL}$. Liver characteristics on ultrasound were normal in $69.2 \%$ (18 cases). Ultrasound liver abnormalities were hepatic steatosis (4 cases), a case of hepatic dysmorphia or homogeneous hepatomegaly (1 case).

\subsection{Effectiveness of Treatment}

Twenty-six patients were treated with interferon alpha + ribavirin, during 48 weeks for the 12 genotype 1 and genotype 4 patients, and during 24 weeks for the 13 genotype 2 patients.

SVR was obtained altogether in 15 patients, i.e. 57.7\%. According to the genotype, SVR was obtained in 4 out of 12 patients of genotype 1 (33.3\%) and in 10 out of 13 patients of genotype $2(76.9 \%)$ with a statistically significant difference $(\mathrm{p}=0.02, \mathrm{OR}=0.11,95 \% \mathrm{CI}=0.02-0.81)$. Thus, SVR was better for genotype 2 than for genotype 1 . Note that among patients who did not respond, three of genotype 1 and two of genotype 2 had discontinued treatment for intolerance.

Similarly, the biochemical response at 6 months after treatment was $76.9 \%$ for genotype 2 (10 patients out of 13 ) and $50 \%$ for genotype 1 (6 patients out of 12 ), but the difference was not statistically significant $(\mathrm{p}=0.09, \mathrm{OR}=0.2,95 \% \mathrm{CI}=$ $0.03-1.33)$.

The only patient with genotype 4 had an SVR and a biochemical response at 6 
months post-treatment.

All genotype included, SVR was 58.8\% (10 cases/17) in non-cirrhotic versus SVR of $55.6 \%$ (5 cases/9) in cirrhotic patients. But this difference was not statistically significant $(\mathrm{p}=0.16, \mathrm{OR}=0.31,95 \% \mathrm{CI}=0.05-1.81)$. In genotype 1 patients with cirrhosis, 2 out of $6(33.3 \%)$ had SVR and 2 out of 6 (33.3\%) also had SVR in non-cirrhotic patients. Among patients of genotype 2 with cirrhosis, SVR was obtained in 2 out of 3 cases (66.7\%) versus 8 out of 10 (80\%) non-cirrhotic patients. But the difference was not statistically significant ( $\mathrm{p}=$ $0.45, \mathrm{OR}=0.29,95 \% \mathrm{CI}=0.003$ - 29.36).

In treated patients, none developed cirrhosis or hepatocarcinoma during treatment. There was only one case of death. The cause of death was hepatocarcinoma 80 weeks after stopping dual therapy because of severe neutropenia and thrombocytopenia.

\subsection{Tolerance of Treatment}

The most common side effects were physical asthenia (23 out of 26), flu-like symptoms (22 out of 26), weight loss ( 21 out of 26), and neutropenia (22 out of 26), thrombocytopenia and anemia (20 cases out of 26 respectively). These results are summarized in Table 1 . Neutropenia was grade 0 in 2 cases, grade 2 in 4 cases, grade 3 in 6 cases, and grade 4 in 10 cases. Thrombocytopenia was grade 0 in 9 cases, grade 1 in 5 cases, grade 2 in 3 cases, and grade 3 in 3 cases. Anemia was grade 0 in 1 case, grade 1 in 14 cases, grade 2 in 3 cases, grade 3 in 1 case and grade 4 in 1 case.

Treatment was discontinued due to severe anemia, thrombocytopenia and neutropenia side effects in 3 genotype 1 and 2 genotype 2 patients.

The management of adverse events occurring with interferon + ribavirin

Table 1. Distribution of adverse effects under conventional dual therapy.

\begin{tabular}{ccc}
\hline & \multicolumn{2}{c}{ IFN + ribavirin } \\
\cline { 2 - 3 } Important asthenia & $\mathrm{n}=26$ & $\%$ \\
Influenza-like Syndrome & 23 & 88.5 \\
Neutropenia & 22 & 84.6 \\
Emaciation & 22 & 84.6 \\
$<10 \%$ & 21 & 80.8 \\
$>10 \%$ & 20 & 95.2 \\
Anemia & 1 & 4.8 \\
Thrombocytopénia & 20 & 76.9 \\
Pruritus & 20 & 76.9 \\
Major headaches & 4 & 15.4 \\
Other & 4 & 15.4 \\
& 2 & 7.7
\end{tabular}


required the prescription of erythropoietin in 15 (57.7\%), granulocyte growth factor in 13 case (50\%) and dose reduction of interferon in 12 cases (46.2\%) and/or ribavirin in 12 cases (46.2\%).

\subsection{Cost of Treatment}

The cost of the pre-therapeutic assessment in the patients to be treated was evaluated at 498,176 FCFA/patient or $851.88 \mathrm{USD}$, according to the prices applied to the CNHU/HKM. The cost of conventional dual therapy and therapeutic monitoring depended on the genotype. Thus for genotype 1 and 4 patients, it was $11,800,624 \mathrm{FCFA} /$ patient or 20,179.07 USD. For genotype 2 patients, it was 7,835,048 FCFA/patient or 13,397.93 USD.

\section{Discussion}

The percentage of patients treated was $54.7 \%$. This rate is relatively low as it is currently recommended to treat all patients with chronic hepatitis C [6] [7]. This low rate is due to the fact that only patients with at least moderate fibrosis ( $\mathrm{F}>$ 1) were selected for treatment. This limitation of access to treatment is explained by a prioritization for economic reasons. In terms of treatment efficacy, in our study, the overall SVR was $57.7 \%$. This result is similar to the $56 \%$ reported in a multicentric study by Fried MW et al. [8]. In genotype 1 patients treated with conventional dual therapy, SVR was $33.3 \%$. This value is lower than those reported by most authors. In different studies around the world, the proportion of genotype $1 \mathrm{HCV}$-infected patients achieving SVR in conventional dual therapy was $40 \%$ in North America and 50\% in Western Europe [9] [10]. According to studies by Fried MW et al. (2002 in North Carolina, USA) and Manns $M$ et al. (2001 in Hanover, Germany), it ranged from $42 \%$ to $46 \%$ for naive genotype 1 patients [8] [11]. Maru et al. (2008 in New Haven, Connecticut (USA)) also found $43.1 \%$ for genotype 1 [12]. Our SVR for genotype 1 is close to the 31.8\% reported by Farley JD et al. in 2005 in Canada [13] and better than the 18\% of SVR reported by Chew KW et al. in 2009 in San Francisco, California, USA [14]; but these two studies were done in a prison population. For genotype 2 , in our study, SVR for conventional dual therapy was $76.9 \%$. This value is similar to that found by McHutchison JG et al. (2009 in the USA) which was 80\% [15]. In studies in America and Western Europe, the SVR for genotype 2 was $80 \%$ [10]. According to studies by Fried MW et al. [8], Hadziyannis SJ et al. [9] and Manns $M$ et al. [11], it was $76 \%$ for naïve patients of genotype 2. The value found in our study is lower than the $100 \%$ mentioned by Farley JD et al. [13]. It is also higher than those of $58.8 \%$ and $60 \%$ respectively found by Maru et al. [12] and Chew et al. [14]. For genotype 4, we had only one genotype 4 patient treated with pegylated interferon + ribavirin for 48 weeks in whom SVR was obtained.

Concerning the predictive factors of response under the classic bitherapy, those especially mentioned are the genotype and the existence or not of a 
cirrhosis [12]. In our study, genotype 2 patients had a significantly better SVR than genotype 1 patients $(\mathrm{p}=0.02)$. Biochemically, there was a biochemical response in $76.9 \%$ of genotype 2 against $50 \%$ of genotype 1 . But this difference was not statistically significant $(\mathrm{p}=0.09)$. Similarly, $58.8 \%$ of non-cirrhotic patients had SVR versus $55.6 \%$ of cirrhotic patients. But this difference was not statistically significant $(\mathrm{p}=0.16)$. The small size of our sample could explain that the difference was not significant.

In terms of safety, in our study, we experienced 5 out of 26 cases $(19.2 \%$ of pegylated interferon + ribavirin patients) of treatment intolerance leading to discontinuation of treatment. These were about severe neutropenia, thrombocytopenia and severe anemia. The most commonly reported adverse events during treatment were physical asthenia (88.5\%), neutropenia (84.6\%), flu-like symptoms (84.6\%), weight loss (80\%), 8\%) and anemia (76.9\%). In the literature, the most commonly reported effects are flu-like symptoms, severe asthenia, depression, irritability, sleep disturbances, skin reactions and dyspnea, neutropenia, anemia, thrombocytopenia and lymphopenia [16].

Finally, with regard to the cost of treatment, the cost of the pre-treatment assessment in the patients to be treated was estimated at 498,176 FCFA or 851.88 USD and was largely supported by the patient. This cost compared to that of the guaranteed minimum wage which is 40,000 FCFA or 68.40 USD is very high. It is 30 times the average per capita expenditure on health in Benin during the same period (37.21 USD) [17]. This has been a brake on the therapeutic management of patients with HCV in Benin, explaining partly the low rate of treated patients. Similarly, for pegylated interferon and ribavirin patients, the cost of treatment and follow-up ranged from 7,835,048 FCFA i.e. 13,397.93 USD for genotype 2 patients to 11,800,624 FCFA i.e. 20,179.07 USD for genotype 1 and 4 . These costs are very high for the standard of living of our population. This is why Benin health authorities have fully covered this cost of products and monitoring under treatment. However, the patient must be able to have performed the pre-therapeutic assessment to access this care. Hope is placed in reducing the costs of generic direct-acting antivirals, in improving the national technical platform (molecular biology, ultrasonic pulse elastometry). This will allow to treat a larger number of patients. Benin could hope to reach the thresholds set by the WHO for the management of viral hepatitis: The Global Strategy for the Health Sector against Viral Hepatitis, developed by WHO, aims to detect $90 \%$ and treat $80 \%$ of people with HBV and HCV by 2030 [2].

The main limitation of this work is the small number of patients treated with the conventional dual therapy, explaining the low power of the study.

\section{Conclusion}

The treatment of HCV with IFN + ribavirin in Benin is effective especially for genotype 2. But its adverse effects are manifold and its cost is high. The switch to direct-acting antivirals (more effective, better tolerated and less expensive) was 
therefore necessary. Access to treatment is currently limited. It is important to set up a program to fight viral hepatitis in Benin, with a treatment component accessible to all.

\section{Conflicts of Interest}

The authors declare no conflicts of interest regarding the publication of this paper.

\section{References}

[1] Trépo, C. (2006) Historique: Saga virologique et médicale de la découverte des virus qui ont révolutionné nos connaissances. In: Trépo, C., Merle, P. and Zoulim, F., Eds., Hépatites Virales $B$ et $C$, John Libbey Eurotext, Paris, 1-7.

[2] World Health Organization (2017) Global Hepatitis Report 2017. WHO, Geneva, 83 p.

[3] Sall Diallo, A. and Malègue D. (2012) Epidémiologie de l'hépatite C. Dev Sante spécial hépatites, 200,18-19.

[4] Shepard, W., Finelli, L. and Alter, M.J. (2005) Global Epidemiology of Hepatitis C Virus Infection. The Lancet Infectious Diseases, 5, 558-567. https://doi.org/10.1016/S1473-3099(05)70216-4

[5] Kodjoh, N. (2015) Situation de la lutte contre les hépatites B et C en Afrique. Med Sante Trop, 22, 141-144.

[6] World Health Organization (WHO) (2016) Guidelines for the Screening, Care and Treatment of Persons with Chronic Hepatitis C Infection. Genève, WHO, 12 p.

[7] Association Française pour l'Etude du Foie (AFEF) (2015) Recommandations AFEF sur la prise en charge des hépatites virales C. AFEF, France, $126 \mathrm{p}$.

[8] Fried, M.W., Shiffman, M., Reddy, K.R., et al. (2002) Peginterferon Alfa-2a plus Ribavirin for Chronic Hepatitis C Virus Infection. New England Journal of Medicine, 347, 975-982. https://doi.org/10.1056/NEJMoa020047

[9] Hadziyannis, S.J., Sette Jr., H., Morgan, T.R., et al. (2004) Peginterferon-alpha2a and Ribavirin Combination Therapy in Chronic Hepatitis C: A Randomized Study of Treatment Duration and Ribavirin Dose. Annals of Internal Medicine, 140, 346-355. https://doi.org/10.7326/0003-4819-140-5-200403020-00010

[10] Antaki, N., Craxi, A., Kamal, S., et al. (2010) The Neglected Hepatitis C Virus Genotypes 4, 5, and 6: An International Consensus Report. Liver International, 30, 342-355. https://doi.org/10.1111/j.1478-3231.2009.02188.x

[11] Manns, M., McHutchinson, J.G., Gordon, S.C., et al. (2001) Peginterferon Alfa-2b plus Ribavirin Compared with Interferon Alfa-2b plus Ribavirin for Initial Treatment of Chronic Hepatitis C: A Randomised Trial. Lancet, 358, 958-965.

https://doi.org/10.1016/S0140-6736(01)06102-5

[12] Maru, D.S., Bruce, R.D., Basu, S. and Altice, F.L. (2008) Clinical Outcomes of Hepatitis C Treatment in a Prison Setting: Feasibility and Effectiveness for Challenging Treatment Populations. Clinical Infectious Diseases, 47, 952-961. https://doi.org/10.1086/591707

[13] Farley, J.D., Wong, V.K., Chung, H.V., et al. (2005) Treatment of Chronic Hepatitis $\mathrm{C}$ in Canadian Prison in Mates. Canadian Journal of Gastroenterology, 19, 153-156. https://doi.org/10.1155/2005/767540

[14] Chew, K.W., Allen, S.A., Taylor, L.E., Rich, J.D. and Feller, E. (2009) Treatment 
Outcomes with Pegylated Interferon and Ribavirin for Male Prisoners with Chronic Hepatitis C. Journal of Clinical Gastroenterology, 43, 686-691. https://doi.org/10.1097/MCG.0b013e31818dd94c

[15] McHutchison, J.G., Lawitz, E.J., Shiffman, M., et al. (2009) Peg Interferon Alfa-2b or Alfa-2a with Ribavirin for Treatment of Hepatitis C Infection. New England Journal of Medicine, 361, 580-593. https://doi.org/10.1056/NEJMoa0808010

[16] Dalibon, P. (2016) Traitements médicamenteux de l'hépatite C. Actual Pharm, 55, 25-29. https://doi.org/10.1016/j.actpha.2015.11.007

[17] Bénin-Dépenses en santé par habitant (\$US Courant). Statistiques. $\underline{\text { http://perspective.usherbrooke.ca/bilan/servlet/BMTendanceStatPays?langue }=\mathrm{fr}}$ 